\section{International Scientific Journal Theoretical \& Applied Science}

p-ISSN: 2308-4944 (print) e-ISSN: 2409-0085 (online)

Year: $2014 \quad$ Issue: $11 \quad$ Volume: 19

Published: $30.11 .2014 \quad$ http://www.T-Science.org

SECTION 7. Mechanics and machine construction.

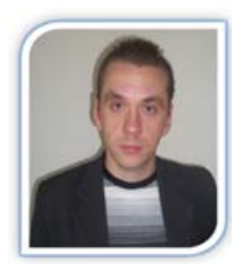

Denis Alexandrovich Chemezov Master of Engineering and

Technology, Lecturer of Vladimir Industrial College,

Russia

chemezov-da@yandex.ru

Nikita Olegovich Kovalenko

Student of

Vladimir Industrial College,

Russia

kovalenko872@gmail.com

\title{
THE CALCULATION OF THE STRESS-STRAIN STATE OF THE LOADED STEPPED SHAFTS IN THE PROGRAM ANSYS HARMONIC RESPONSE
}

\begin{abstract}
The article presents the results of modeling of stress and strain state of the stepped shaft under the influence of torques. The dependences of the amplitude of stresses and amplitude directional acceleration of strain from a specified range of frequencies show a full picture of the state of loaded surfaces of the shaft.

Key words: amplitude, shaft, stress, frequency, material.

Language: Russian

Citation: Chemezov DA, Kovalenko NO (2014) THE CALCULATION OF THE STRESS-STRAIN STATE OF THE LOADED STEPPED SHAFTS IN THE PROGRAM ANSYS HARMONIC RESPONSE. ISJ Theoretical \& Applied Science 11 (19): 30-40. doi: http://dx.doi.org/10.15863/TAS.2014.11.19.7

\section{УДК 621.824.2}

\section{РАСЧЕТ НАПРЯЖЕННО-ДЕФОРМИРОВАННОГО СОСТОЯНИЯ НАГРУЖЕННЫХ СТУПЕНЧАТЫХ ВАЛОВ В ПРОГРАММЕ ANSYS HARMONIC RESPONSE}

Аннотация: В статье представлены результаты моделирования напряженного и деформированного состояния ступенчатого вала при действии на него моментов сил. Зависимости амплитуды напряжений и амплитуды направленного ускорения деформации от заданного диапазона частот, демонстрируют полную картину состояния нагруженных поверхностей вала.

Ключевые слова: амплитуда, вал, напряжение, частота, материал.
\end{abstract}

Валы применяются в тех случаях, когда необходимо передать определенную величину вращающего момента посредством установленных на них зубчатых колес, шкивов, звездочек и других вращающихся деталей [1].

В процессе эксплуатации, валы воспринимают различные по величине и направлению нагрузки. Наиболее часто, валы подвергаются изгибу и кручению. При этом в материале, из которого изготовлена деталь, возникают деформации и напряжения от приложенной нагрузки. Это негативно сказывается на нормальной работе технологического оборудования и приводит к снижению точности обработки деталей.

Для определения прочности вала при действии нагрузок, необходимо определить максимальное расчетное значение напряжение в материале детали и затем сравнить его с предельно допустимым [2]. Описание методики проведения исследования с применением компьютерных технологий, позволит выполнять комплексный расчет напряженнодеформированного состояния материала детали с различными геометрическими формами и линейными/диаметральными размерами.

Исследование выполнялось в четыре этапа с описанием выполняемых действий.

1. Анализ детали в соответствии с рабочим чертежом [3].

Расчет напряженно-деформированного состояния производился для многоступенчатой детали «Вал». Восемь ступеней вала выполняют функции посадочных, крепежных и свободных поверхностей. Общая длина вала составляет 230 мм. Две посадочные поверхности (после резьбовых поверхностей) предназначены для 
установки подшипников, имеют $\varnothing 25 k 6\left(\begin{array}{l}+0,015 \\ +0,002\end{array}\right)$

мм и длины 18 мм и 24 мм, соответственно. Поверхности (со шпоночными пазами) для установки и крепления зубчатых колес на вал имеют Ø $26 n 6\left(\begin{array}{l}+0,028 \\ +0,015\end{array}\right)$ мм, длину 27 мм и Ø $30 n 6$ $\left(\begin{array}{l}+0,028 \\ +0,015\end{array}\right)$ мм, длину 59 мм. Для выхода абразивного инструмента во время шлифования посадочных поверхностей, предусмотрены две канавки шириной 3 мм, глубиной 0,3 мм с образованием радиусной поверхности $R 1$ мм. Крепление детали в узле технологического оборудования обеспечивается резьбами $M 22 \times 1,5-8 g$ на длине 18 мм и $M 24 \times 1,5-8 g$ на длине 19 мм. На резьбах выполняются две фаски $2 \times 45^{\circ}$. Свободными размерами вала являются наибольшие Ø 35 мм и Ø 40 мм, имеющие плавный переход фаской $5 \times 35^{\circ}$. На валу выполнены два закрытых шпоночных паза размерами $8 \times 5 \times 10$ мм и $8 \times 4 \times 22$ мм (радиус закругления паза, образующийся от фрезы 4 мм, внутренние закругления - не более 0,4 мм). Масса детали - 1,25 кг, объем - 159,64 $\mathrm{CM}^{3}$.

2. Построение объемной твердотельной модели детали в программной среде Ansys [4].

Возможно создание трехмерной модели в CAD-системах «легкого» класса (например,
Компас) с последующим сохранением файла в формате IGES [5] и импортом в систему Ansys.

3. Постановка задачи (задание начальных условий имитационного моделирования).

Решение выполнялось в модуле Harmonic Response [6] в следующей последовательности [7]:

a) Принятие материала детали (Material Data) - конструкционная сталь со следующими физико-механическими свойствами: плотность -

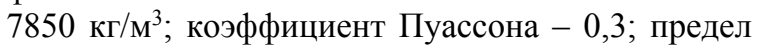
текучести - 2,5 × $10^{8}$ Па; предел прочности - 4,6 $\times 10^{8}$ Па; модуль упругости $-2 \times 10^{11}$ Па.

б) Разбиение твердотельной модели детали (Mesh) на 93762 узла (62431 элемент) для выполнения высокой точности расчета. Концентрация элементов представлена на рис. 1.

в) Приложение нагрузок (Loads) - два момента сил, величиной $120 \mathrm{H} \times$ м и $150 \mathrm{H} \times$ м, направленных в одном направлении и действующих на диаметрах детали со шпоночными пазами (рис. 2). Фиксация вала - за наружные диаметры под подшипники.

г) Задание параметров анализа (Analysis Settings): частотный диапазон $0-50$ Гц, интервалы решения - $10(5,10,15,20,25,30,35$, $40,45,50)$, решение задачи - метод наложения.

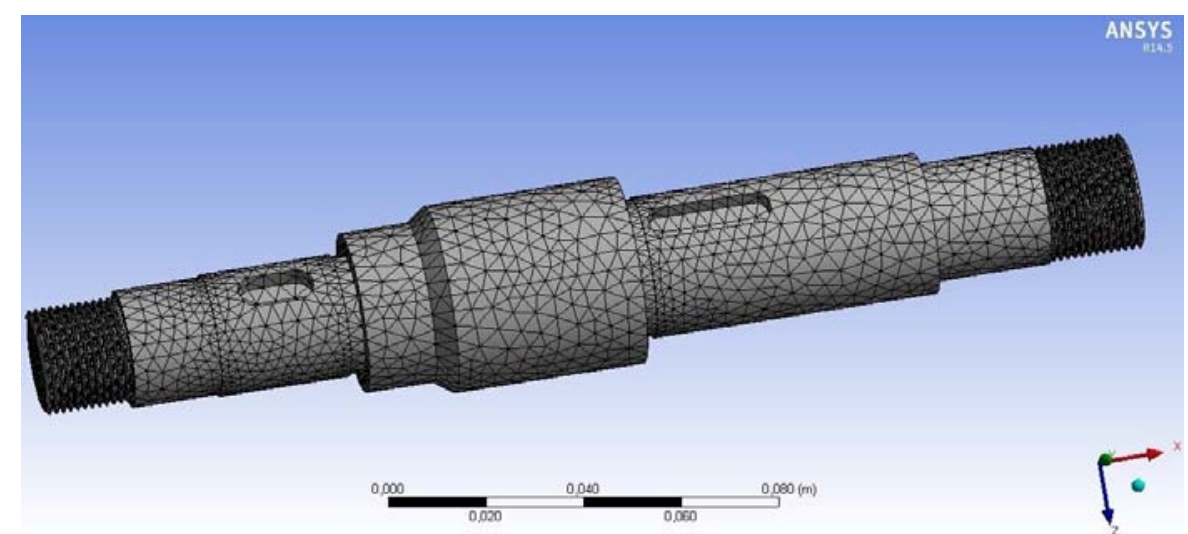

Рисунок 1 - Разбиение твердотельной модели ступенчатого вала

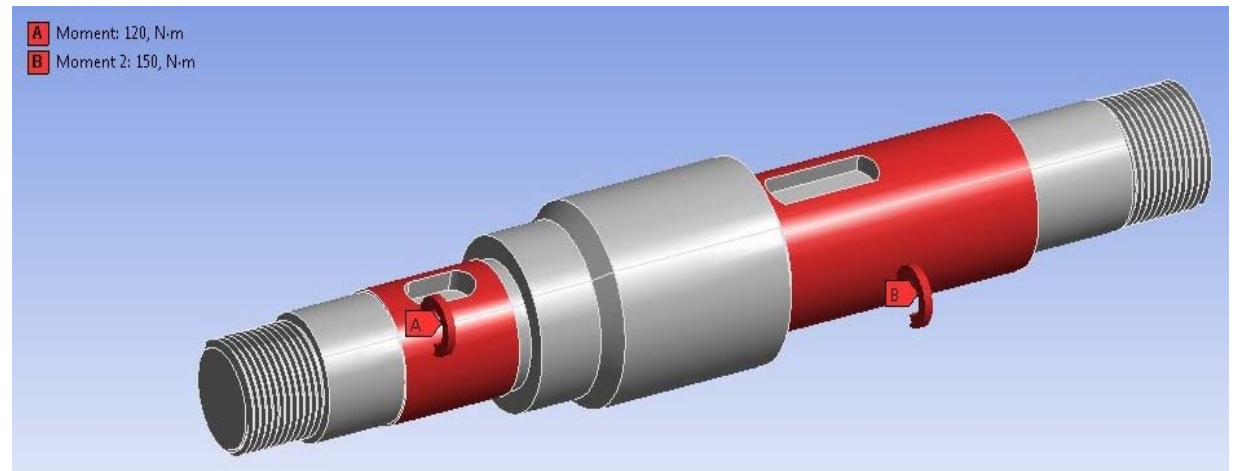

Рисунок 2 - Приложение (направление) моментов сил на ступени вала: А - 120 Н × м; В - 150 Н × м 


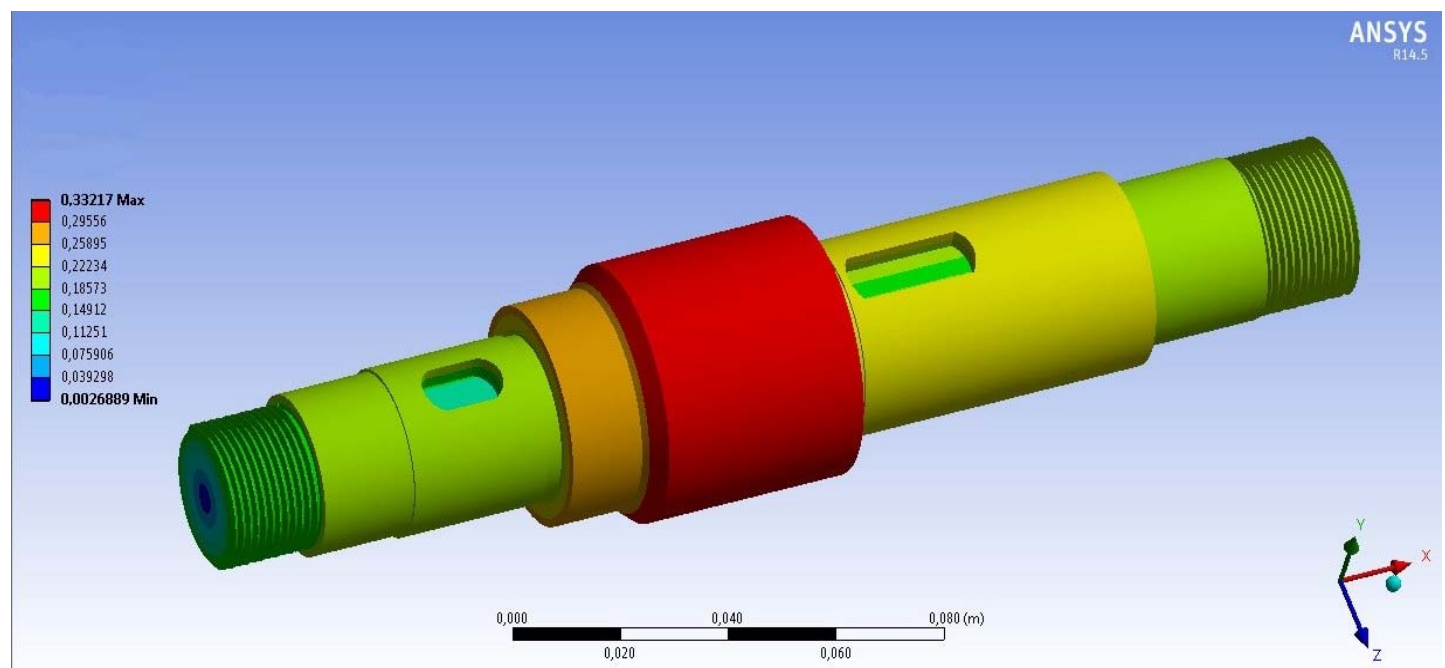

Рисунок 3 - Полная деформация вала на частоте 50 Гц и фазовом угле $5^{\circ}$. Единица измерения м

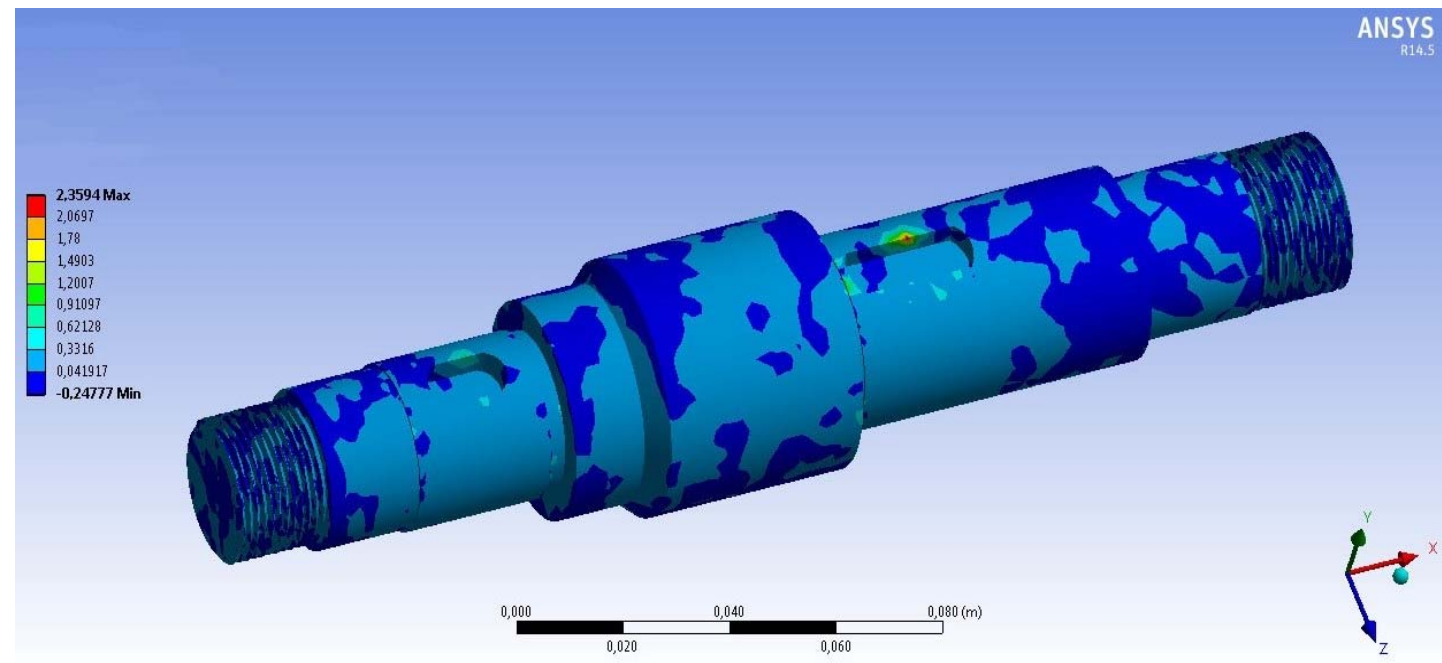

Рисунок 4 - Максимальное главное напряжение вала на частоте 50 Гц и фазовом угле $5^{\circ}$. Единица измерения Па

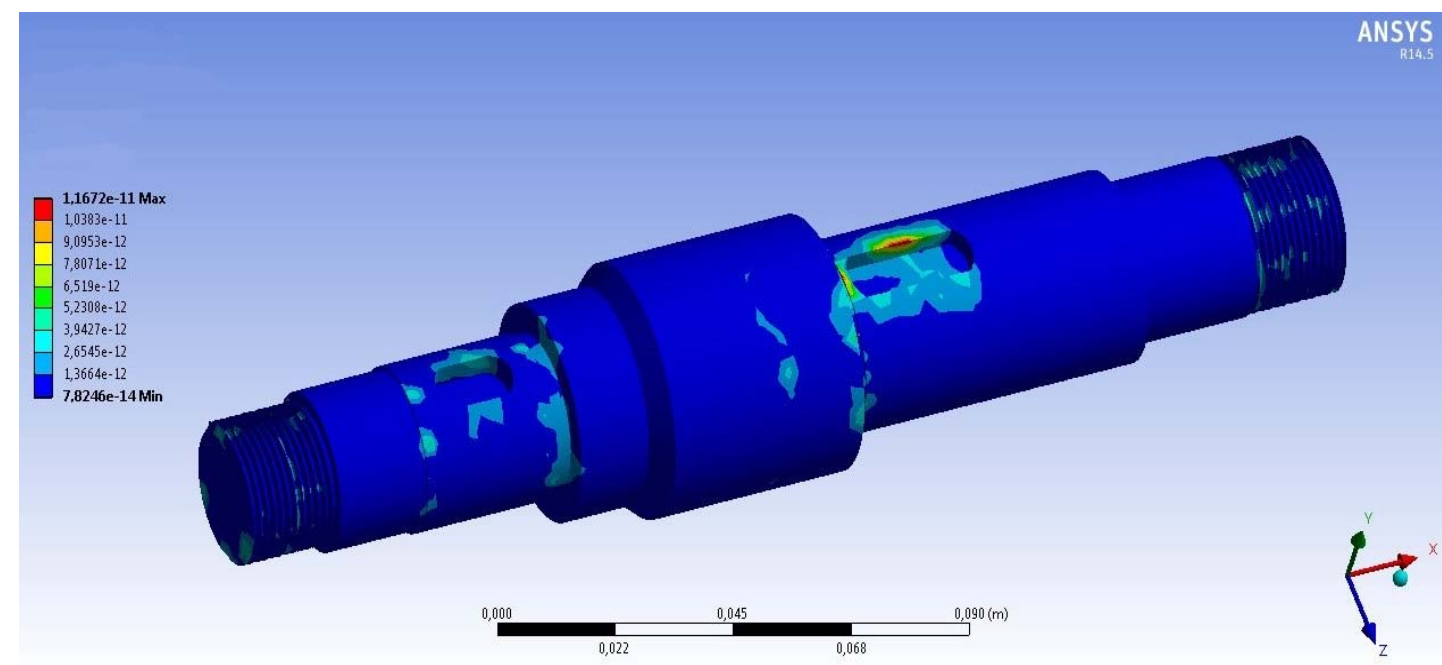

Рисунок 5 - Эквивалентная упругая деформация вала на частоте 50 Гц и фазовом угле $5^{\circ}$. Единица измерения м/м 


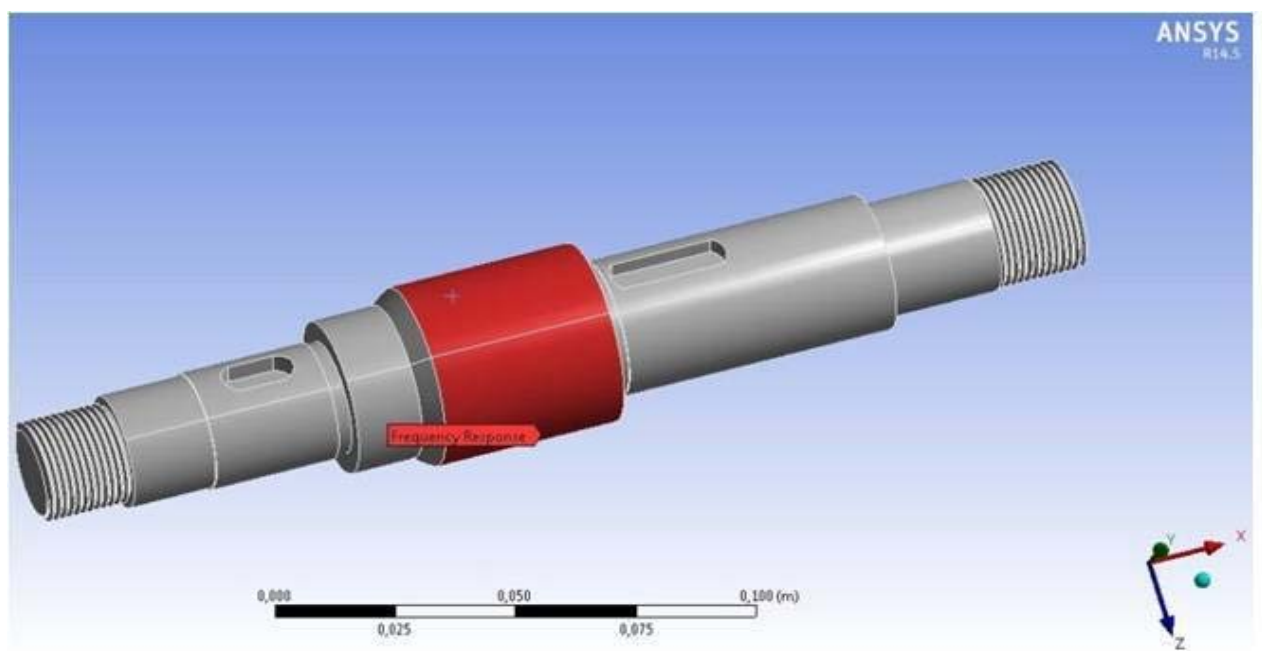

a)

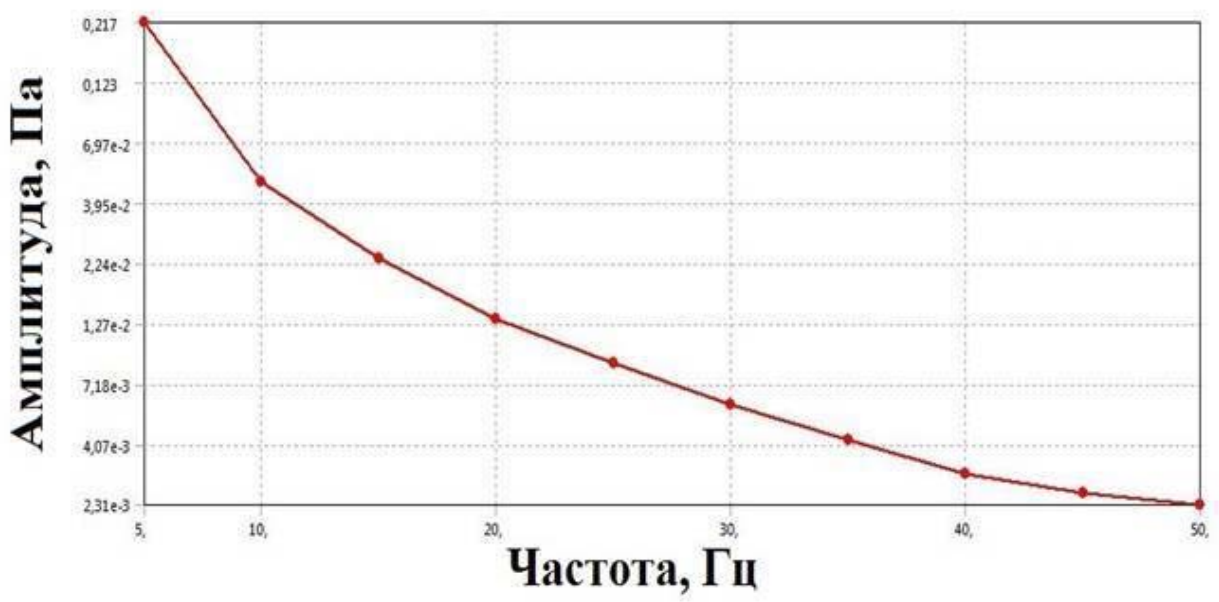

б)

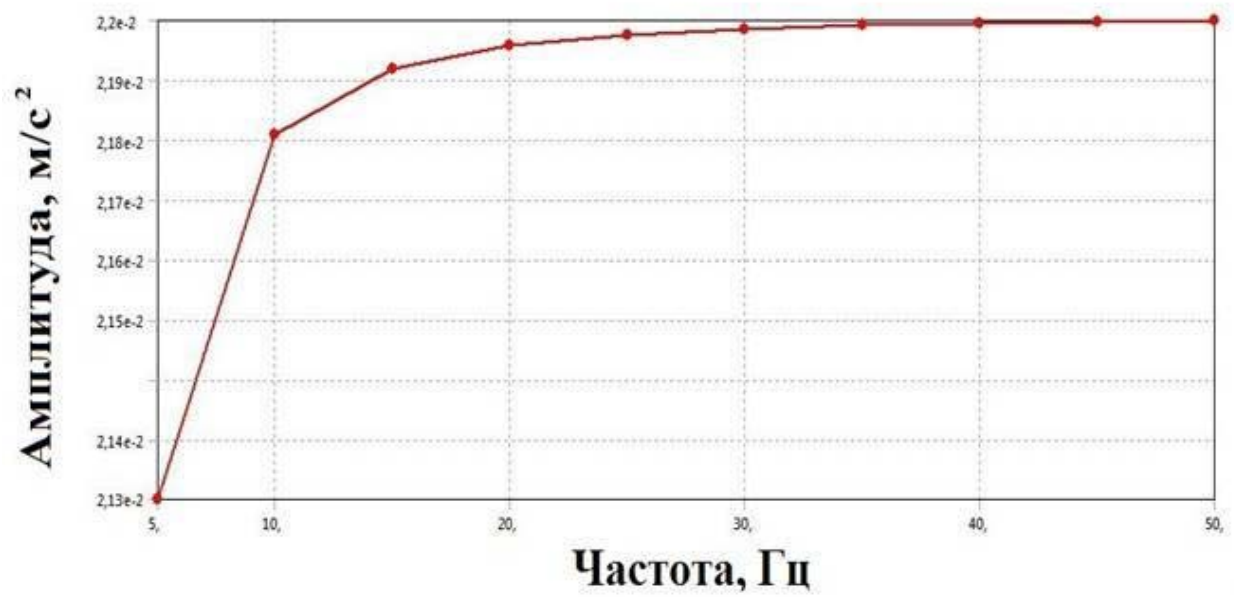

B)

Рисунок 6 - Характеристики частотного отклика: а - поверхность вала (Ø 40 мм), с которой снимались показания; б - зависимость амплитуды напряжений от частоты; в - зависимость амплитуды направленного ускорения деформации от частоты

\section{4. Решение и анализ результатов} моделирования.

Процесс решения сопровождается обновлением текущих результатов на новые через 2,5 сек, при действии нагрузки на каждом частотном интервале. Результаты расчета представлены в виде эпюры, представляющей собой наложенную цветовую гамму на модель детали. На рис. 3 - 5 отображены эпюры полной деформации, максимального главного напряжения и эквивалентной упругой деформации вала на 50 Гц и фазовом угле $5^{\circ}$.

Отмечено, что максимальной деформации подвергаются наибольшие наружные диаметра вала (Ø 40 мм), минимальной - объем материала расположенный ближе к оси детали. Упругие 
деформации вала сосредоточены на краях шпоночных пазов. Напряжение распределено локальными участками на всех поверхностях детали. Характеры изменения амплитуд напряжений и направленного ускорения от величины частоты, определенные в результате отклика выбранных поверхностей вала, графически представлены на рис. 6 - 12 .

\author{
Impact Factor JIF \\ $=1.500$ \\ Impact Factor GIF (Australia) $=\mathbf{0 . 3 5 6}$ \\ Impact Factor SIS (USA)
}

Для $\varnothing \quad 40$ мм определены следующие зависимости амплитуд: наибольшая величина напряжения материала возникает в момент приложения нагрузок, и при дальнейшем их действии уменьшается до достижения минимального значения на частоте 50 Гц; на всем частотном диапазоне, направленное ускорение деформации материала не значительно увеличивается (на $\left.0,07 \times 10^{-2} \mathrm{M} / \mathrm{c}^{2}\right)$.

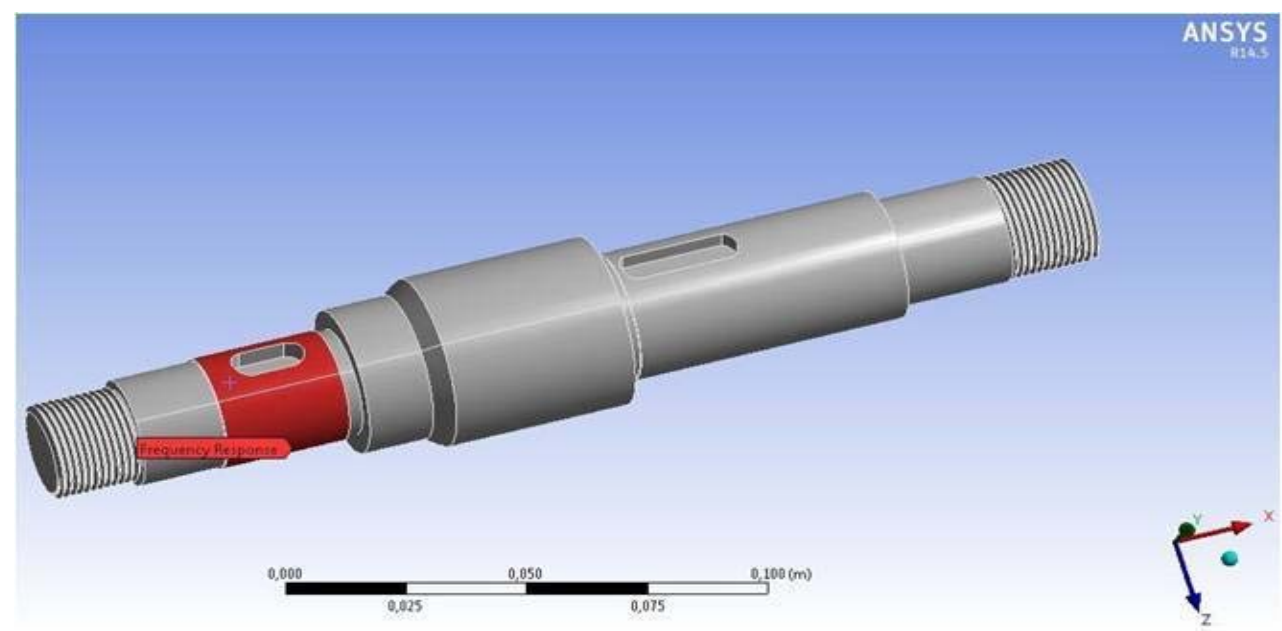

a)

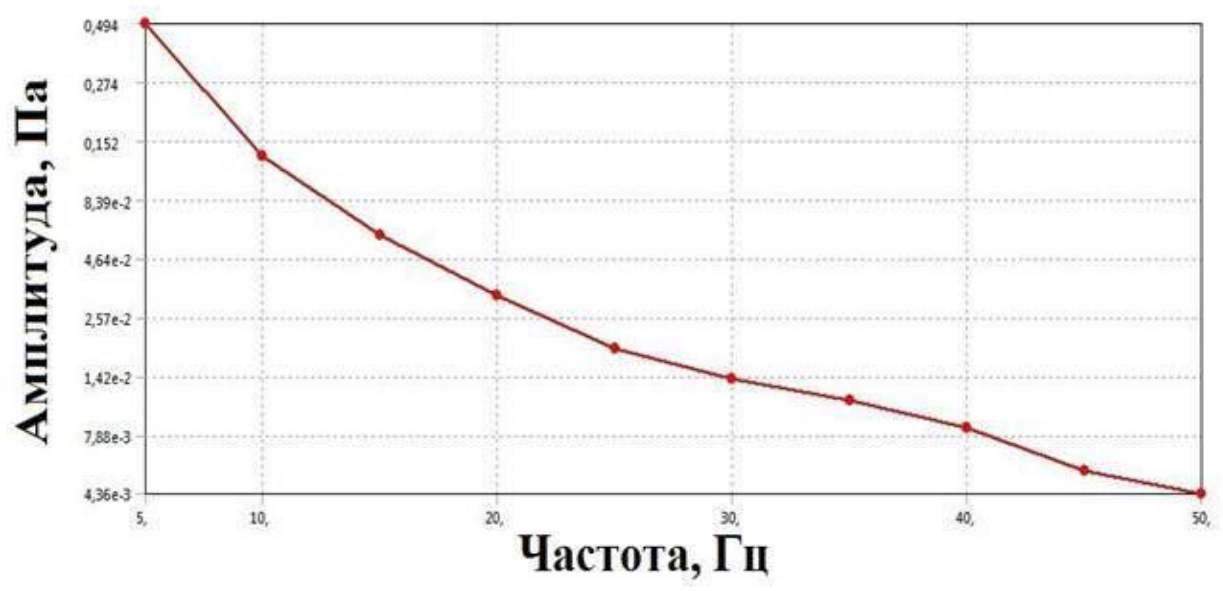

6)

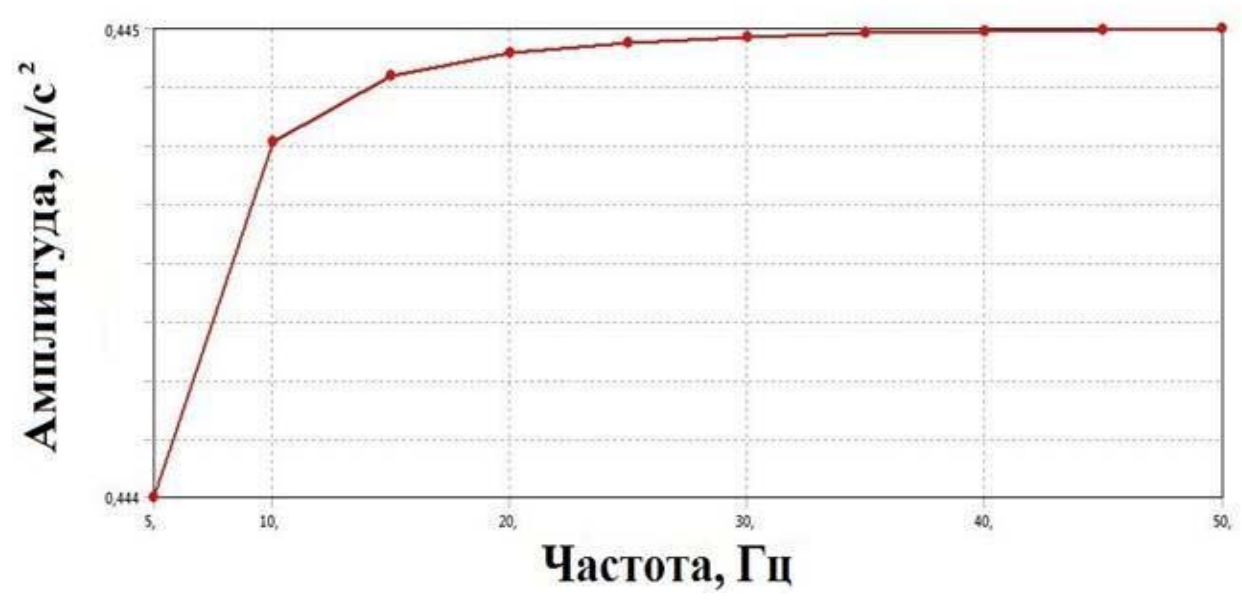

B)

Рисунок 7 - Характеристики частотного отклика: а - поверхность вала (Ø 26 мм), с которой снимались показания; б - зависимость амплитуды напряжений от частоты; в - зависимость амплитуды направленного ускорения деформации от частоты 
Для $\varnothing 26$ мм определены следующие зависимости амплитуд: размах (уменьшение) амплитуды напряжения материала составляет 0,48964 Па на частотном диапазоне $0-50$ Гц (характер изменения величины - линейный, без резких уменьшений); на всем частотном диапазоне расчета, направленное ускорение деформации материала детали не значительно увеличивается.

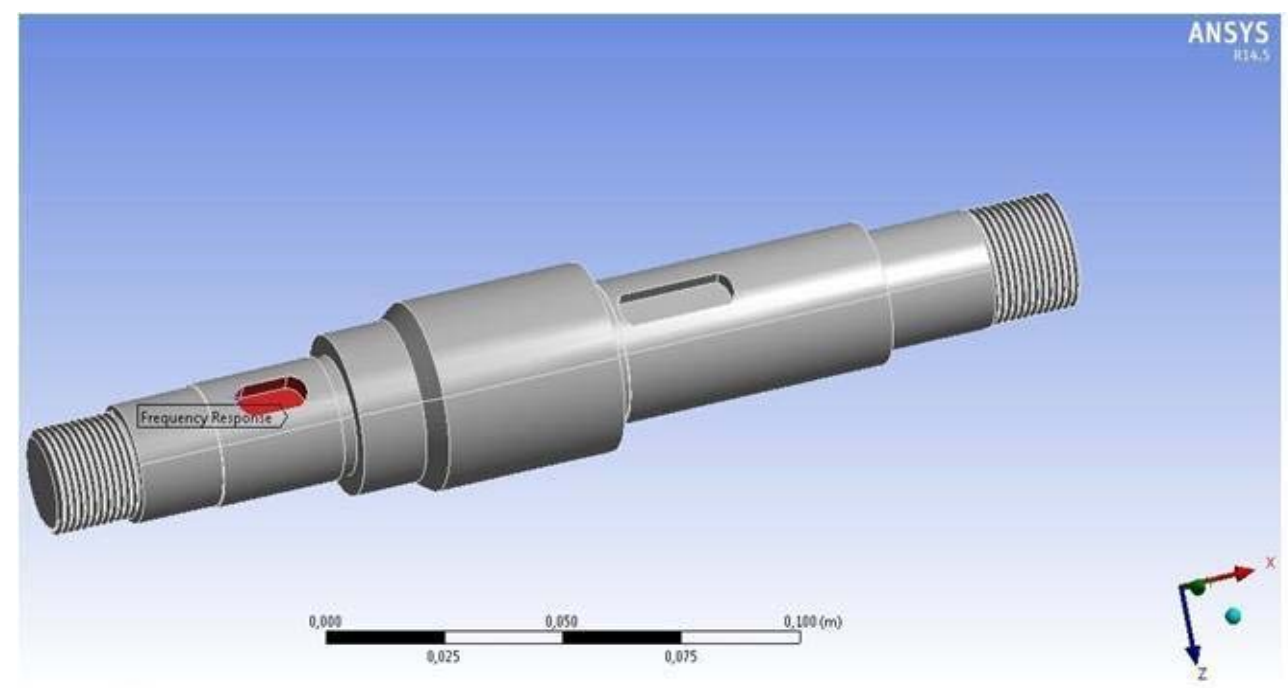

a)

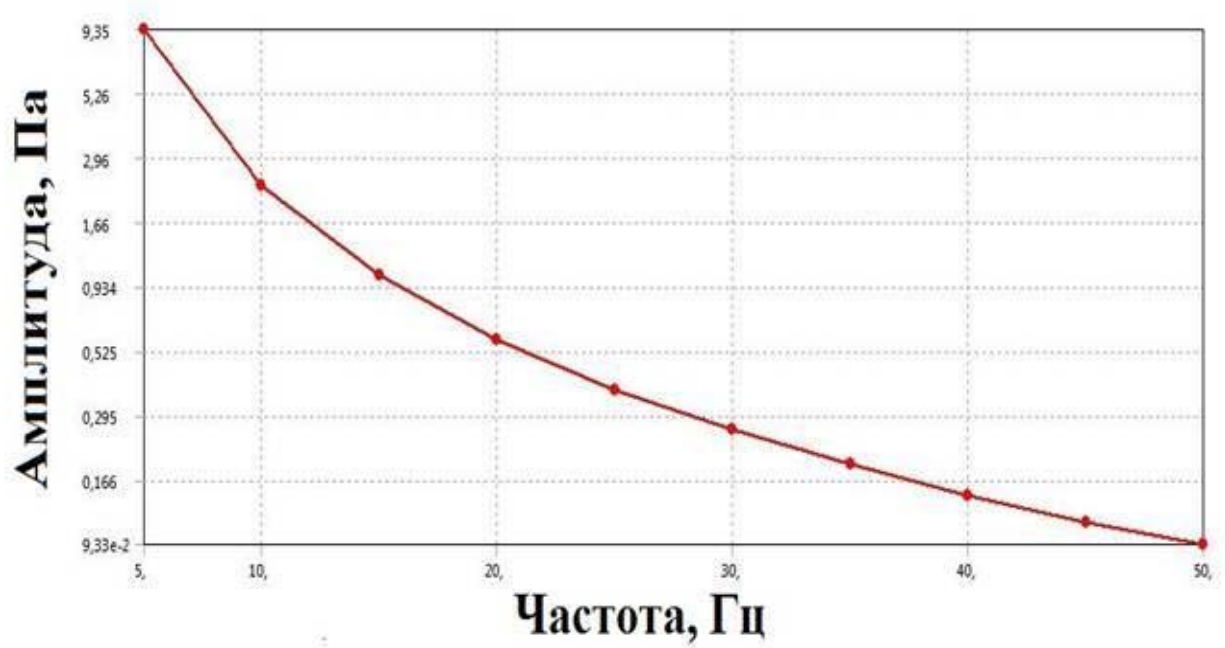

6)

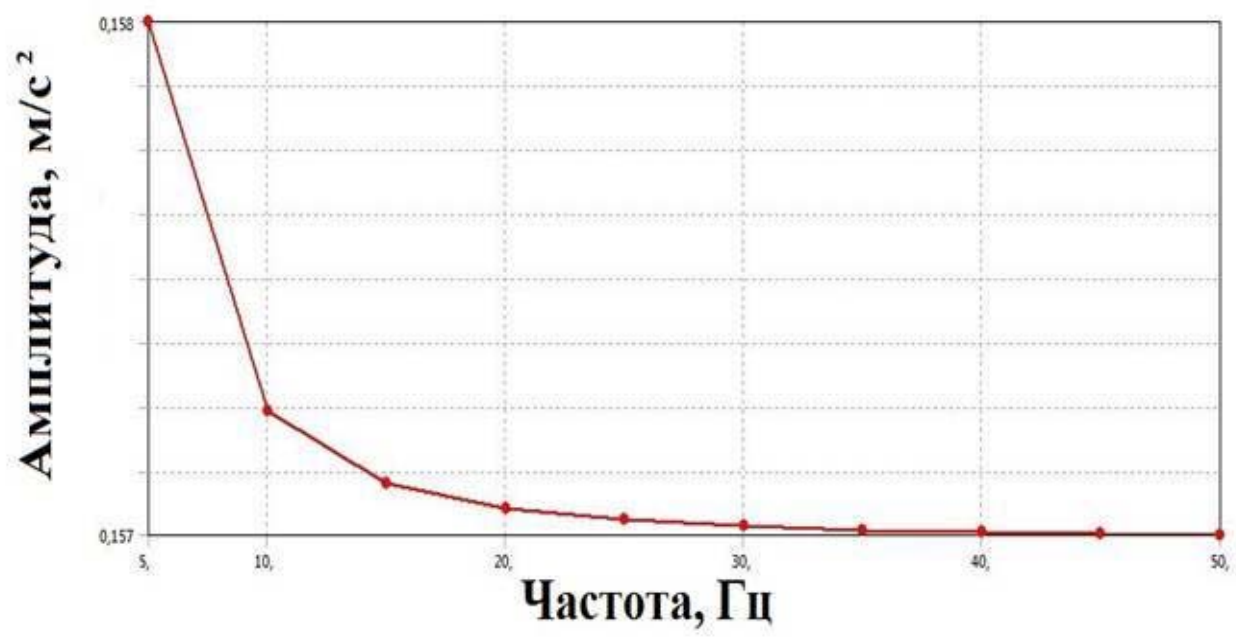

B)

Рисунок 8 - Характеристики частотного отклика: а - поверхность вала (шпоночный паз Ø 26 мм), с которой снимались показания; б - зависимость амплитуды напряжений от частоты; в зависимость амплитуды направленного ускорения деформации от частоты 
Для шпоночного паза Ø 26 мм определены следующие зависимости амплитуд: размах (уменьшение) амплитуды напряжения материала составляет 9,2567 Па на частотном диапазоне 0 50 Гц; величина направленного ускорения деформации материала детали не значительно уменьшается. При расчете учитывались боковые присоединительные поверхности шпоночного паза.

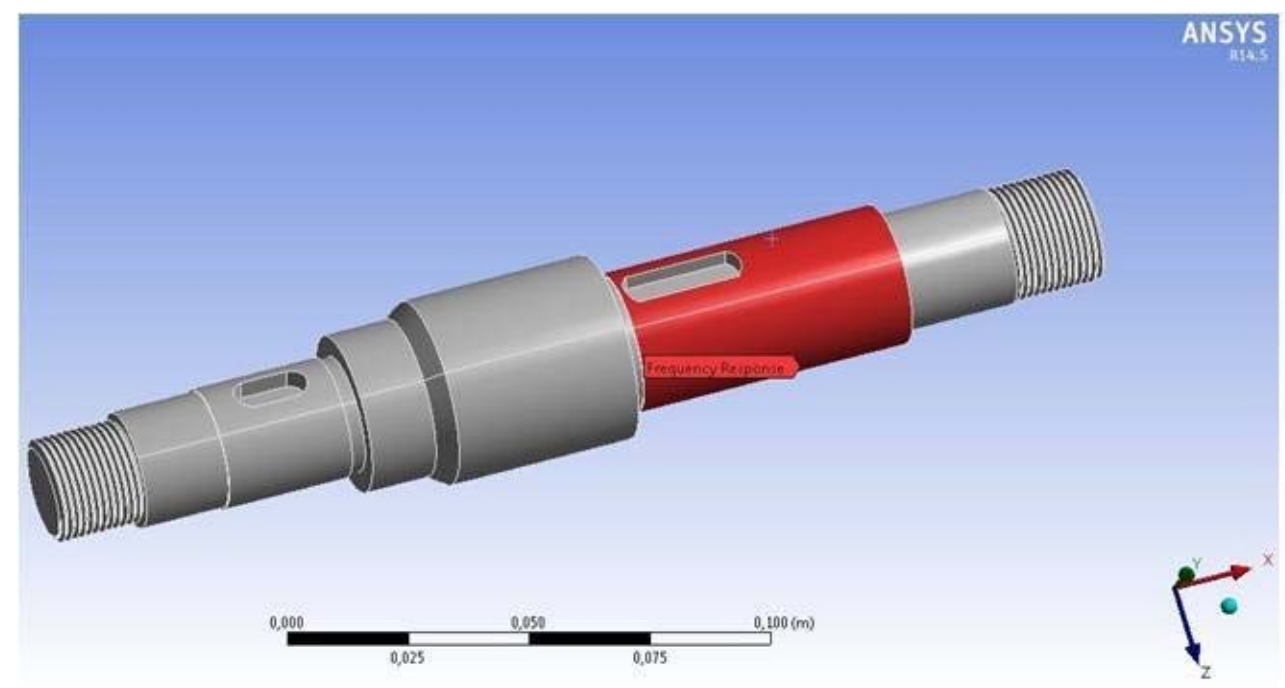

a)

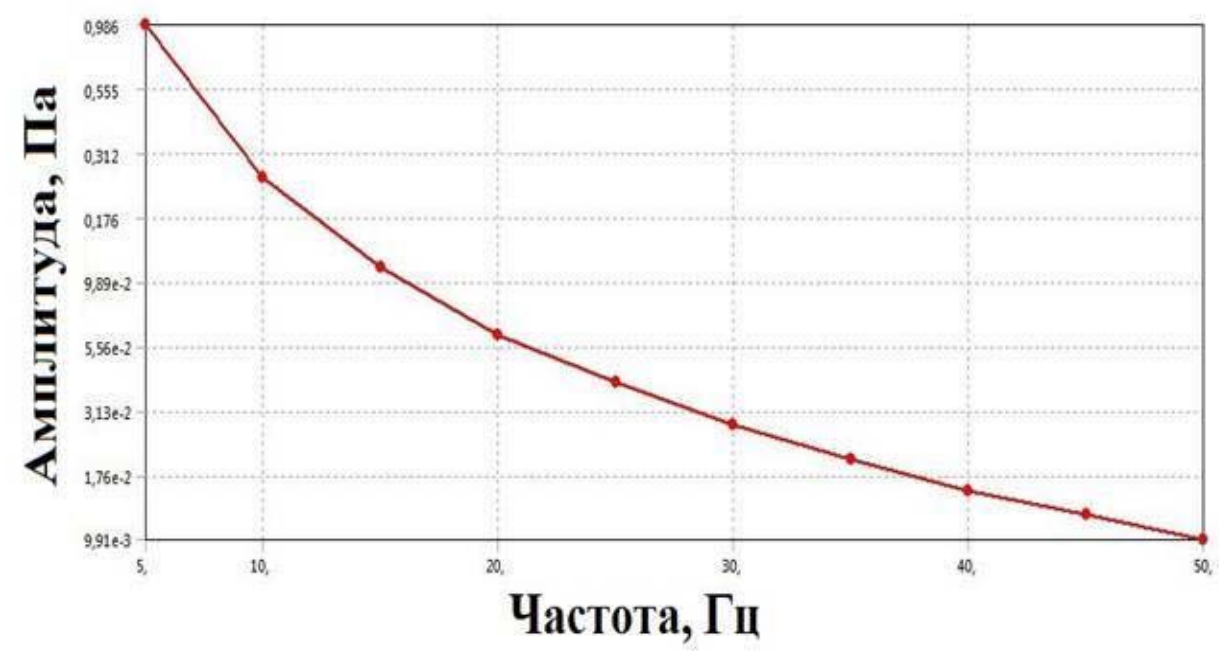

6)

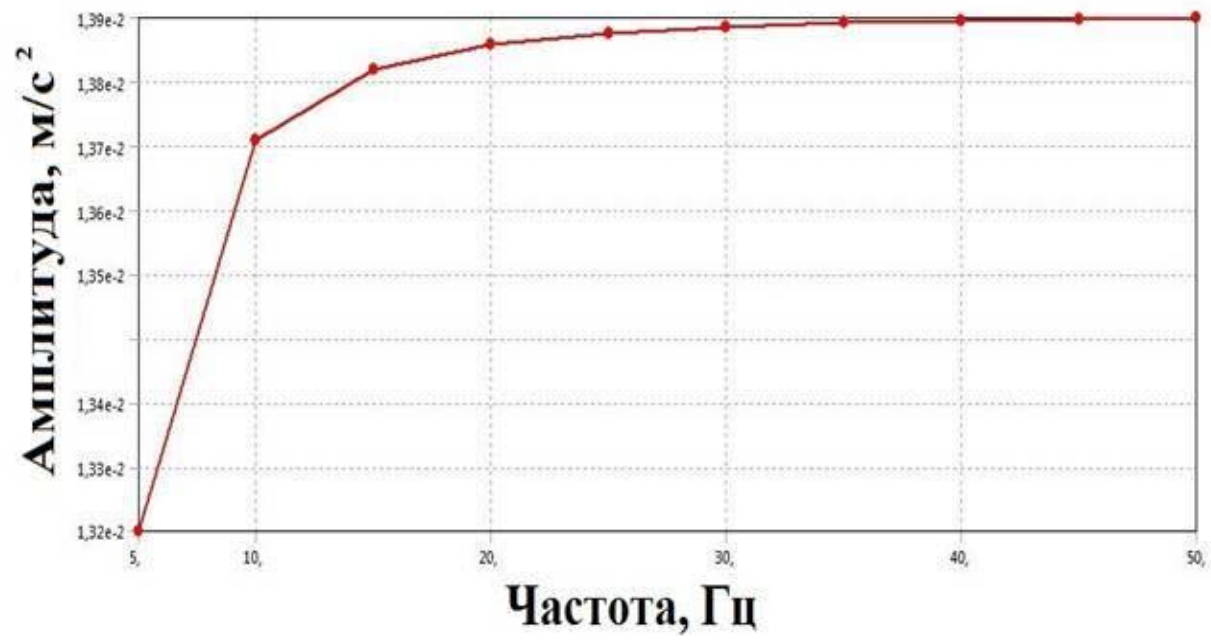

B)

Рисунок 9 - Характеристики частотного отклика: а - поверхность вала (Ø 30 мм), с которой снимались показания; б - зависимость амплитуды напряжений от частоты; в - зависимость амплитуды направленного ускорения деформации от частоты 
Для $\varnothing \quad 30$ мм определены следующие зависимости амплитуд: размах (уменьшение) амплитуды напряжения материала составляет 0,97609 Па на частотном диапазоне 0 - 50 Гц; величина направленного ускорения деформации материала детали не значительно увеличивается на всем частотном диапазоне $\left(0,07 \times 10^{-2} \mathrm{M} / \mathrm{c}^{2}\right)$. Для расчета принята поверхность детали без учета шпоночного паза.

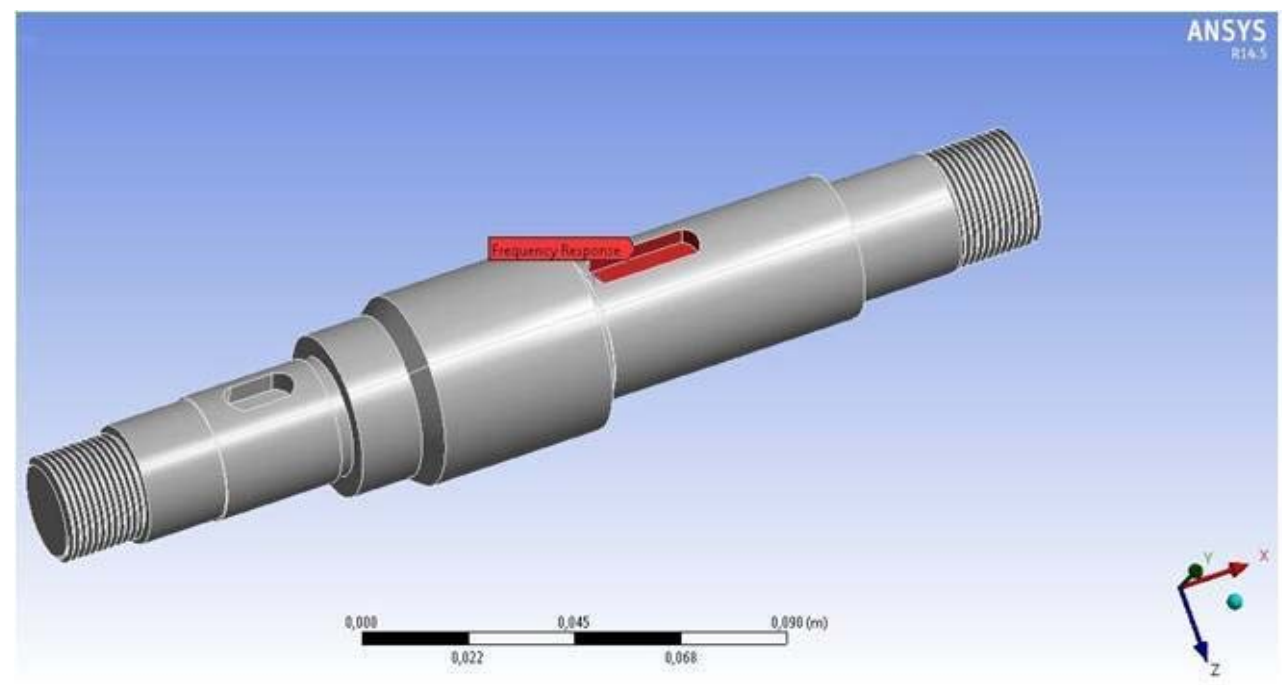

a)

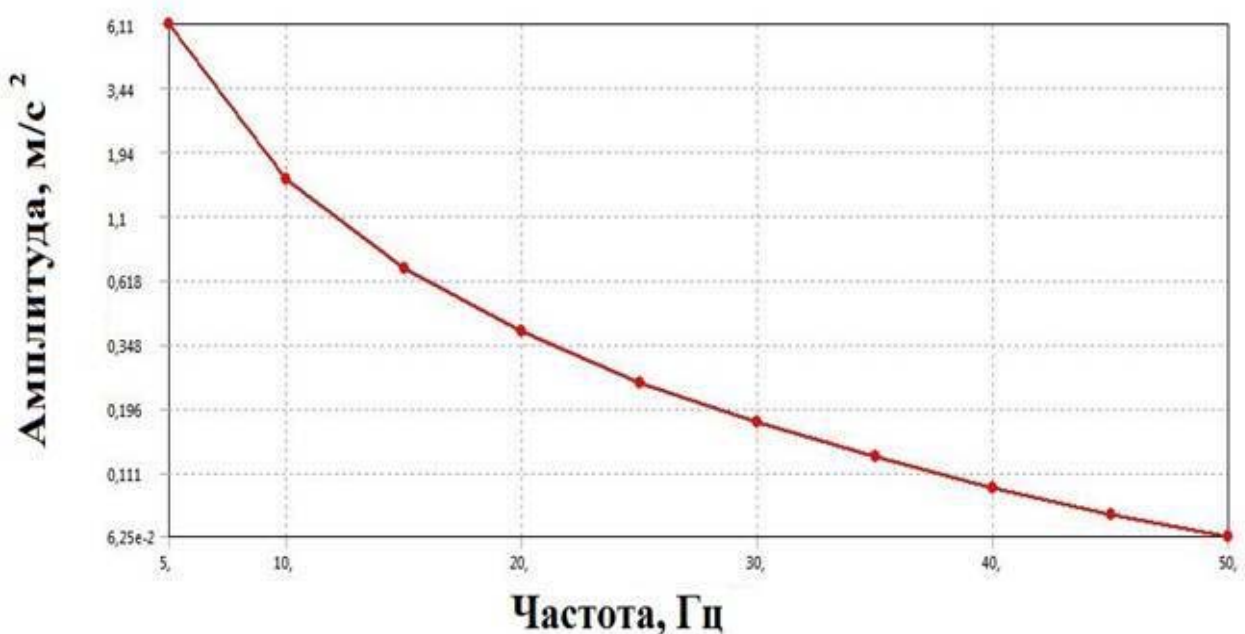

б)

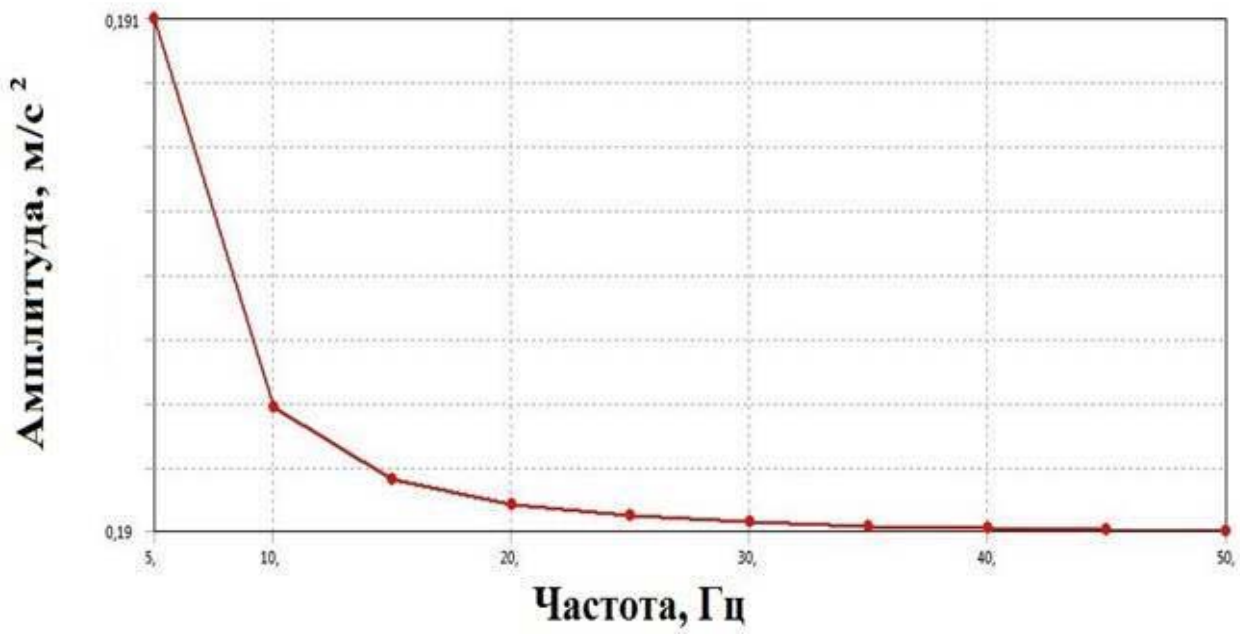

B)

Рисунок 10 - Характеристики частотного отклика: а - поверхность вала (шпоночный паз Ø 30 мм), с которой снимались показания; б - зависимость амплитуды напряжений от частоты; в зависимость амплитуды направленного ускорения деформации от частоты 
Для шпоночного паза Ø 30 мм определены следующие зависимости амплитуд: размах (уменьшение) амплитуды напряжения материала составляет 6,0475 Па на частотном диапазоне 0 50 Гц; величина направленного ускорения деформации материала детали не значительно уменьшается. При расчете учитывались боковые присоединительные поверхности шпоночного паза.

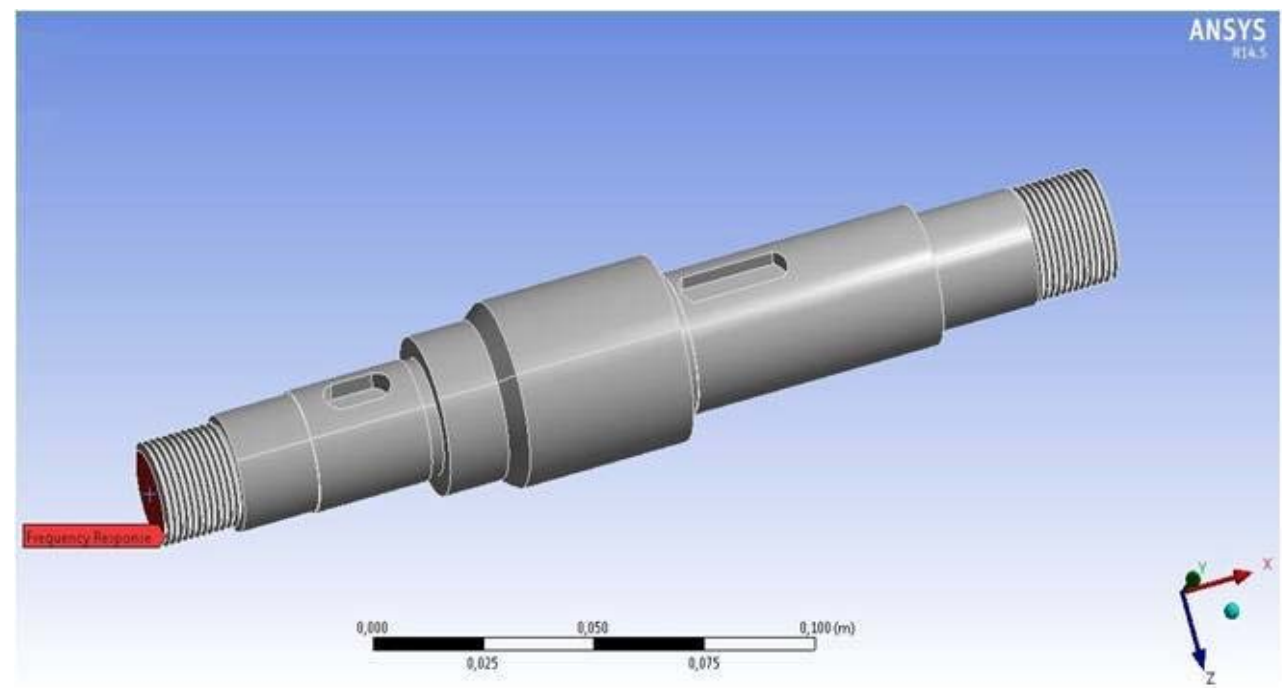

a)

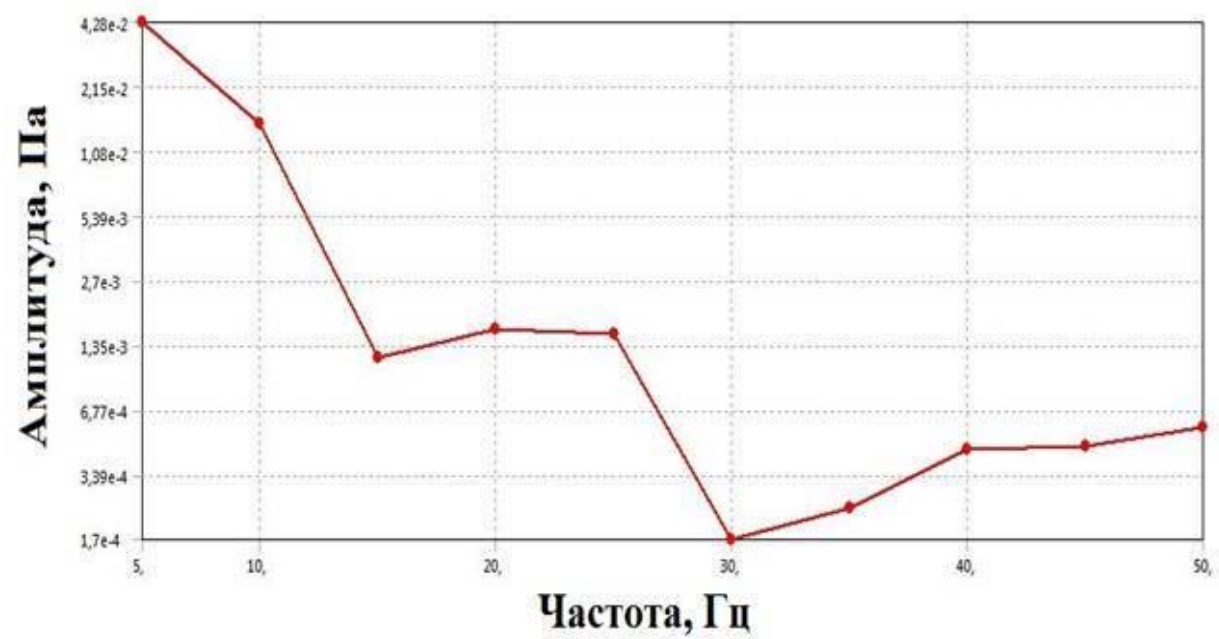

6)

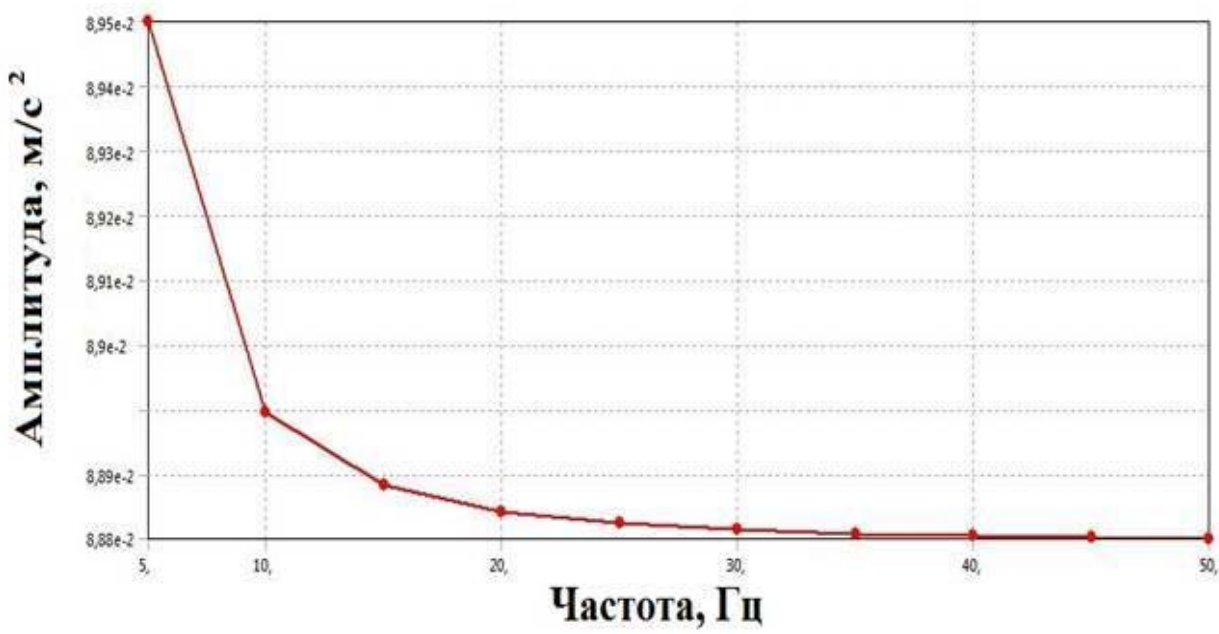

B)

Рисунок 11 - Характеристики частотного отклика: а - поверхность вала (торцевая поверхность со стороны резьбы), с которой снимались показания; б - зависимость амплитуды напряжений от частоты; в - зависимость амплитуды направленного ускорения деформации от частоты 
Для торцевой поверхности со стороны резьбы определены следующие зависимости амплитуд: размах амплитуды напряжения материала представлен в виде возрастающих (в интервалах 15 - 20 Гц и $30-50$ Гц) и убывающих (в интервалах 5 - 15 Гц и 20 - 30 Гц) функций; величина направленного ускорения деформации материала детали не значительно уменьшается (на $\left.0,07 \times 10^{-2} \mathrm{M} / \mathrm{c}^{2}\right)$.

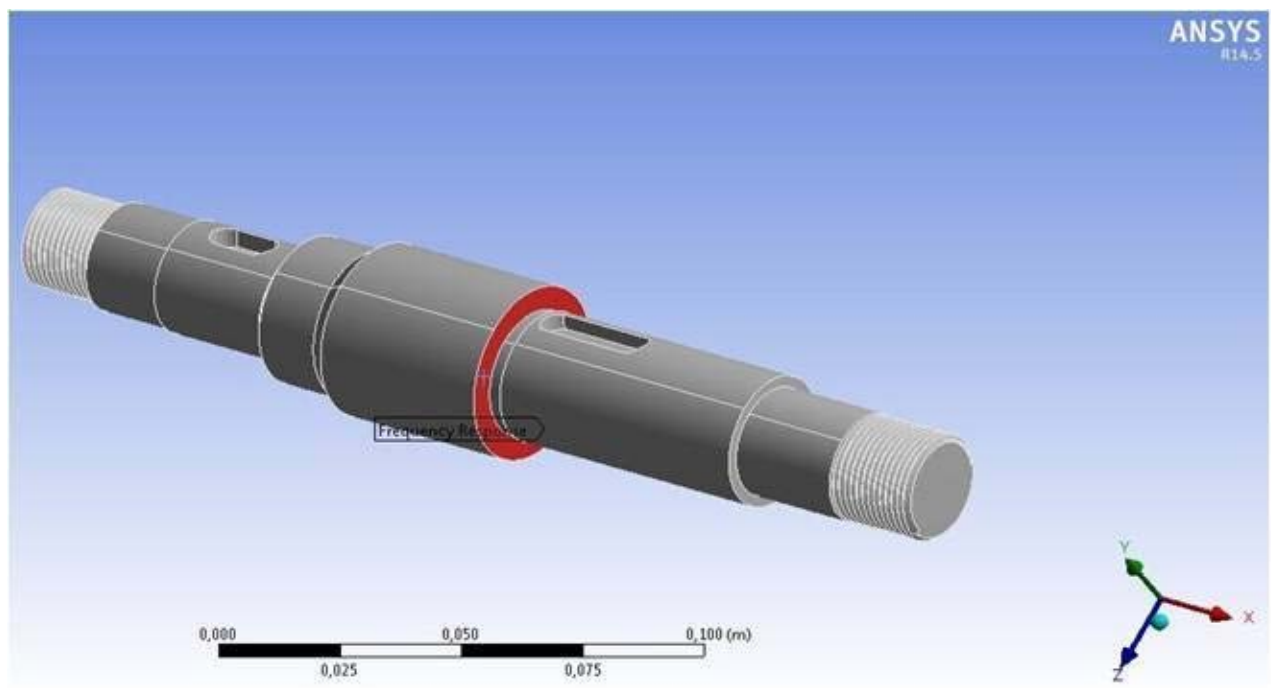

a)

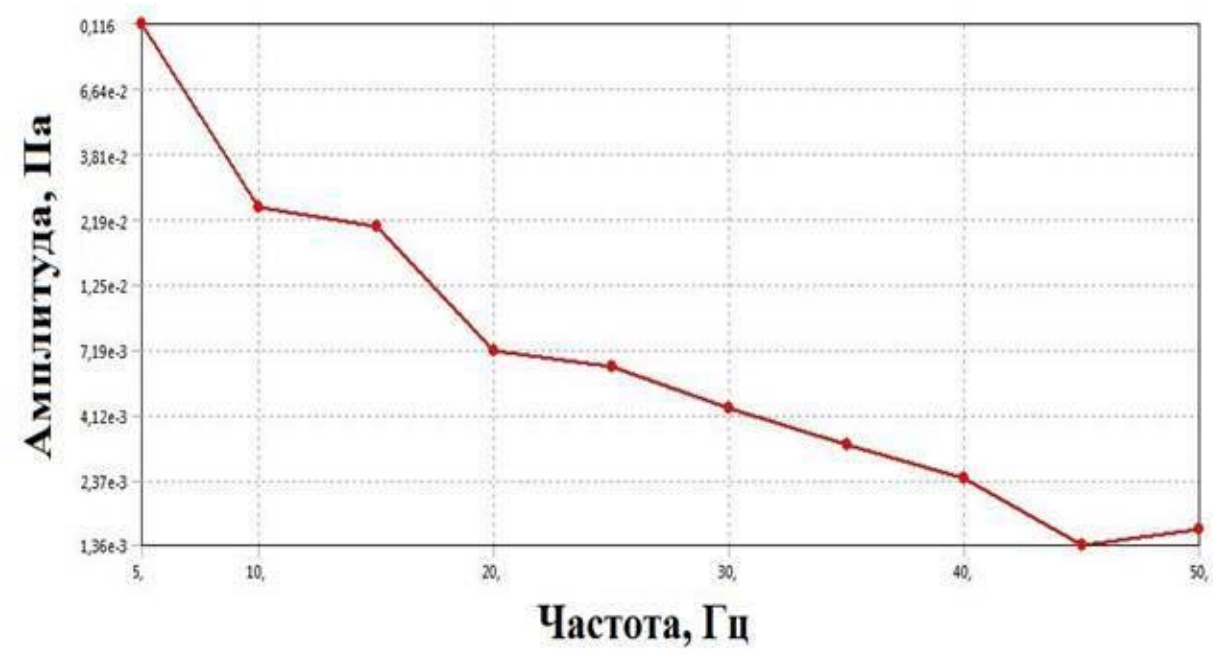

6)

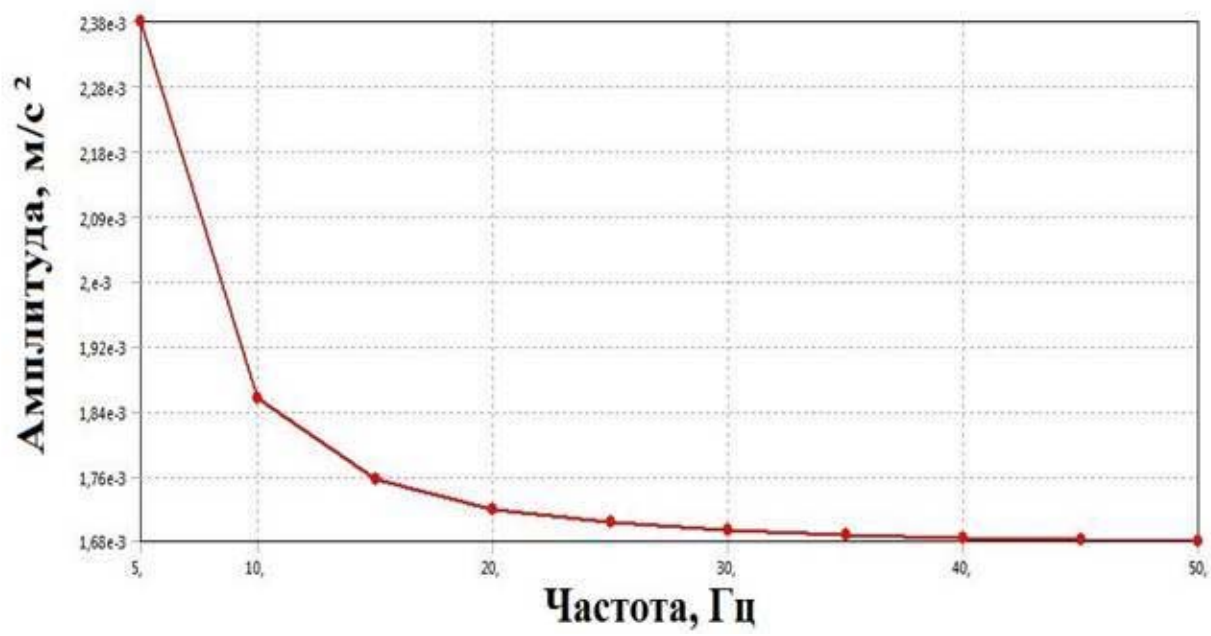

B)

Рисунок 12 - Характеристики частотного отклика: а - поверхность вала (торцевая поверхность Ø 40 мм), с которой снимались показания; б - зависимость амплитуды напряжений от частоты; в зависимость амплитуды направленного ускорения деформации от частоты 
Для торцевой поверхности Ø 40 мм определены следующие зависимости амплитуд: напряжение материала на частотном интервале 5 - 45 Гц уменьшается, с 45 Гц увеличивается; величина направленного ускорения деформации материала детали постоянно уменьшается.

Результаты реализации имитационного моделирования напряженно-деформированного состояния ступенчатого вала при действии на него различных по величине и одинаковых по направлению моментов сил, представлены в сводной табл. 1. Значения напряжения материала детали, выделенные красным цветом максимальные, зеленым - минимальные.

Результаты расчета

Таблица 1

\begin{tabular}{|c|c|c|c|c|c|c|c|}
\hline \multirow[b]{2}{*}{$\begin{array}{c}\text { Наименование } \\
\text { и единица } \\
\text { измерения } \\
\text { параметров }\end{array}$} & \multicolumn{7}{|c|}{ Поверхности детали } \\
\hline & $\varnothing 40$ мм & $\begin{array}{c}\varnothing 26 \\
\text { мM }\end{array}$ & $\begin{array}{c}\text { шпон. } \\
\text { паз } \\
\text { Ø } 26 \text { мм }\end{array}$ & Ø 30 мм & $\begin{array}{c}\text { шпон. } \\
\text { паз } \\
\varnothing 30 \text { мм }\end{array}$ & $\begin{array}{c}\text { торцевая } \\
\text { поверхн. со } \\
\text { стороны } \\
\text { резьбы }\end{array}$ & $\begin{array}{c}\text { торцевая } \\
\text { поверхн. } \\
\varnothing 40 \text { мм }\end{array}$ \\
\hline $\begin{array}{c}\text { Макс. } \\
\text { амплитуда, } \\
\text { Па }\end{array}$ & 0,217 & 0,494 & 9,35 & 0,986 & 6,11 & $4,28 \times 10^{-2}$ & 0,116 \\
\hline 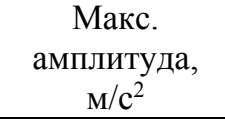 & $2,2 \times 10^{-2}$ & 0,445 & 0,158 & $1,39 \times 10^{-2}$ & 0,191 & $8,95 \times 10^{-2}$ & $2,38 \times 10^{-3}$ \\
\hline
\end{tabular}

В соответствии с расчетом, определено, что максимальные напряжения возникают на поверхностях шпоночных пазов при непосредственном действии моментов сил. По мере удаления от места приложения нагрузок, напряжение в материале детали уменьшается. Для шпоночного паза Ø 26 мм вала получена математическая модель (1) изменения величины напряжения материала от частоты и момента силы величиной $120 \mathrm{H} \times$ м $[8,9]$.

$$
\sigma={ }_{k_{1}}-{ }_{k_{2}} \times \vec{M}-{ }_{k_{3}} \times f
$$

где $\sigma$ - напряжение; $k_{1}, k_{2}, k_{3}$ - коэффициенты, значения которых зависят от величин момента силы и частоты; $M$ - момент силы; $f$ - частота. При этом должно выполняться следующее условие для коэффициентов: $k_{1}>k_{2}<k_{3}$.

\section{References:}

1. (2014) Valy i osi. Available:

http://www.prikladmeh.ru/lect6.htm (Accessed: 16.11.2014).

2. (2014) Valy i osi. Osnovy rascheta na prochnost', jestkost' i vynoslivost'. Available: http://3ys.ru/detali-mashin-i-osnovykonstruirovaniya/valy-i-osi-osnovy-rascheta-naprochnost-zhestkost-i-vynoslivost.html (Accessed: 16.11.2014).

3. (2014) Nadpisi na chertejah. Available: http:/cdot-nntu.ru/basebook/ng2/system/ theory/rab chert iframe.HTM (Accessed: 16.11.2014).

4. (2014) AnSYS. Available: http:/www.pandia.ru/text/78/170/98891-5.php (Accessed: 16.11.2014).

5. (2014) Preprocessor. Import geometricheskih modelei. Available: http://sio.su/manual 079 16 gen.html (Accessed: 16.11.2014).
6. (2014) Base acceleration in harmonic analysis using Ansys Mechanical (Workbench) V14.5. Available:http://www.simutechgroup.com/FEA/ fea-tips-tricks-ansys-base-accelerationharmonic-analysis.html (Accessed: 16.11.2014).

7. (2014) Etapy reshenia zadachi v programmnom komplekse ANSYS. Available: http://lib.exdat.com/docs/966/index-114191.html (Accessed: 16.11.2014).

8. (2014) Uravnenie regressii, opredelenie ego parametrov. Available:

http://uchebnikionline.com/statistika/statistika _oprya at/rivnyannya regresiyi viznachennya yogo parametriv.htm (Accessed: 16.11.2014).

9. (2014) Mnojestvennaia regressia. Available: http://www.statsoft.ru/home/textbook/modules/ stmulreg.html (Accessed: 16.11.2014). 